\title{
Usage Patterns of Electric Bicycles: An Analysis of the WeBike Project
}

\author{
Christian Gorenflo, Ivan Rios, Lukasz Golab, and Srinivasan Keshav
}

University of Waterloo, Waterloo, ON, Canada N2L $3 G 1$

Correspondence should be addressed to Christian Gorenflo; cgorenflo@uwaterloo.ca

Received 7 April 2017; Accepted 24 August 2017; Published 9 October 2017

Academic Editor: Chi Xie

Copyright (C) 2017 Christian Gorenflo et al. This is an open access article distributed under the Creative Commons Attribution License, which permits unrestricted use, distribution, and reproduction in any medium, provided the original work is properly cited.

\begin{abstract}
This paper presents an analysis of data collected through the Waterloo WeBike project: a field trial in which over 30 sensor-equipped electric bicycles (e-bikes) were given to members of the University of Waterloo for personal use. Our dataset includes e-bike trips and battery charging sessions spanning nearly three years, from summer 2014 until spring 2017. We also conducted three surveys both before and during the trial. Our main findings were that the primary purpose of the e-bikes in our trial was for commuting, with most trips lasting less than 20 minutes and most trips taking place in the summer months. Our battery charging analysis revealed no evidence of range anxiety, and our analysis of survey results showed little correlation between anticipated and actual use. Furthermore, when asked about their opinions about various modes of transportation, our participants rated regular bicycles higher than e-bikes even after becoming familiar with e-bikes through the field trial. Based on our analysis, we draw several conclusions, including the fact that the general population in Canada is still unaware of e-bikes and their potential. Moreover, e-bike manufacturers should target sales to nonbike users, such as seniors, rather than trying to displace sales of regular bicycles.
\end{abstract}

\section{Introduction}

Motivated by the environmental, public health, ecological, and carbon-footprint issues associated with gasolinepowered automobiles, researchers, governments, and society as a whole have been engaged in a search for viable alternatives. Electric bicycles (e-bikes), which are propelled by a combination of pedaling and battery-powered electric motors, are a promising alternative to automobile transportation. Their primary advantages include lower purchase and operating costs compared to cars, ability to travel longer distances and with less physical effort compared to traditional bicycles, and zero emissions during operation.

Given these benefits, e-bike adoption is accelerating globally, with over 200 million being used in China alone [1]. This has led to several studies on the social and environmental impacts of e-bikes in China (e.g., [2-5]). Furthermore, in 2015, 28 percent of all bicycle sales in the Netherlands were e-bikes [6]. These trends are expected to lead to rapid adoption of e-bikes in these geographies. For example, Navigant Research estimates that the global e-bike market will reach
USD 24.3 billion by 2025, with nearly 35 million unit sales estimated for 2016 [7].

In contrast, little is known about North American use patterns, where barriers to adoption of e-bikes include a lack of widespread acceptance of cycling as a viable alternative to conventional transportation and cold winters with poor road conditions. North American municipalities are keen to explore low-carbon alternatives for transportation such as ebikes, both to create more livable cities and to reduce the carbon footprint of the transportation sector. However, they lack data to make evidence-based recommendations.

To address this gap, we are conducting a three-year field trial at the University of Waterloo, whose purpose is to collect real e-bike usage data. In this field trial, called WeBike [8], a fleet of approximately 30 sensor-equipped ebikes were distributed to Waterloo faculty/staff members and students for their own use. Since the summer of 2014 until now (April 2017), we have collected over 150 gigabytes of GPS, acceleration, and battery charge and discharge data. Furthermore, we have conducted three surveys, one per year, asking each participant about their sentiments towards 
TABLE 1: Summary of previous e-bike field studies.

\begin{tabular}{lccccc}
\hline Reference & Purpose & Location & Participants & Duration & Data collected \\
\hline Kiefer and Behrendt [17] & Usage & Brighton, UK & 30 bikes/93 riders & 10 months & GPS, assistance level, accelerometer \\
Fyhri and Fearnley [18] & Usage & Norway & 66 & $2-4$ weeks & Odometer \\
Paefgen and Michahelles [19] & Usage & Switzerland & 17 & 4 months & GPS \\
MacArthur et al. [23] & Usage & Portland, OR, USA & 30 bikes & 1.5 years & Participant surveys \\
Dozza et al. [24] & Safety & Gothenburg, SE & 3 bikes/12 riders & 2 weeks & Video, GPS, braking force, lateral movement \\
Langford et al. [25] & Safety & Knoxville, TN, USA & 12 bikes & 2 years & GPS \\
Schleinitz et al. [26] & Speed & Germany & 85 & 4 weeks & Video, speedometer \\
Fluchter and Wortmann [20] & IoT issues & Switzerland & 32 bikes & 4 months & GPS \\
\hline
\end{tabular}

different modes of transportation. Additionally, the first survey asked the participants about how often they anticipate to use their e-bike.

This paper presents an analysis of this data. We make the following three contributions:

(1) We present algorithms to identify trips and charging sessions from raw collected data; while this may seem simple, challenges arise due to noisy and incomplete sensing data.

(2) We analyze trip statistics and battery charging patterns and highlight differences between faculty/staff members and students' usage.

(3) We analyze participant survey responses. We show participants' sentiments towards various modes of transportation, and we compare participants' initial estimates of how much they would ride their bikes with actual riding histories.

The remainder of this paper is organized as follows. Section 2 discusses related work. Section 3 gives an overview of the WeBike project and the collected data. In Section 4, we discuss our methodology, including algorithms to detect trips and battery charging sessions from the collected data. Section 5 presents our e-bike usage analysis, followed by participant survey analysis in Section 6. Section 7 concludes the paper with directions for future work.

An early version of this work was presented at the 2016 workshop on Electric Vehicle Systems, Data and Applications (EV-Sys) [9]. New content in this paper includes an expanded and updated related work, algorithmic details of trip and charge cycle identification (Section 4), updated usage and survey analysis (Sections 5 and 6.1; the original workshop paper used data only up to fall 2015), and new survey sentiment analysis (Section 6.2).

\section{Related Work}

Electrically powered transportation avoids or reduces a significant portion of the environmental impact of transportation. While much of the emphasis in the past has been on electric automobiles, attention has recently been increasingly focused on electric bicycles, which have tremendous potential as a zero-point-source-emission solution for urban transportation $[2,10,11]$. E-bikes are rapidly gaining acceptance as a desirable and viable alternative, and there is increasing municipal and consumer readiness to invest in cycling in general and in e-bikes specifically [12-14]. Current urbaninfrastructure planning trends also explore e-bike adoption to improve population health [15] due to increased physical activity, particularly for aging populations and others with restricted mobility [16].

The work closest to ours are recent e-bike field studies summarized in Table 1. Of these, our work is most similar to Kiefer and Behrendt [17], Fyhri and Fearnley [18], Paefgen and Michahelles [19], and Flüchter and Wortmann [20] which also focus on usage patterns. Kiefer and Behrendt collected GPS and motor assistance level data, but they emphasized developing a hardware system reusable by other research groups rather than data analysis. Fyhri and Fearnley collected odometer data and found that participants who were given e-bikes made longer and more frequent trips than those with regular bicycles. The increase in trip frequency and distance was greater for female cyclists. The study reported by Paefgen and Michahelles involved e-bikes with GPS data loggers, with the participant base consisting of employees of an insurance company. However, the published results only describe data from two e-bikes, both of which were used mainly for commuting in the morning and in the afternoon. Flüchter and Wortmann explored user expectations and privacy issues, as well as technological shortcomings in GPS and GSM technologies. Their study did not gather any other sensor data.

Another project distributed e-bikes to Kaiser employees in the Portland, Oregon region, and asked participants to fill out surveys regarding their e-bike usage [21-23]. Their findings coincided with other studies in that e-bikes lower mobility barriers and lead to more frequent and longer trips. However, they did not obtain conclusive results regarding first/last mile commuting because not enough participants used their e-bikes in that way.

Two e-bike field trials focused on safety issues. The first of these, Dozza et al. [24], used three fully instrumented bikes with front and rear cameras as well as brake pressure sensors. The data was used to identify potential safety issues related to sudden movement or braking. The main conclusion from this study was that e-bikes are faster than regular bikes and therefore new safety issues may arise when e-bikes interact with other vehicles on the road. Furthermore, the trips recorded in this study had an average duration of 14 minutes and an average speed of $17 \mathrm{~km} / \mathrm{h}$. The second safety-related 


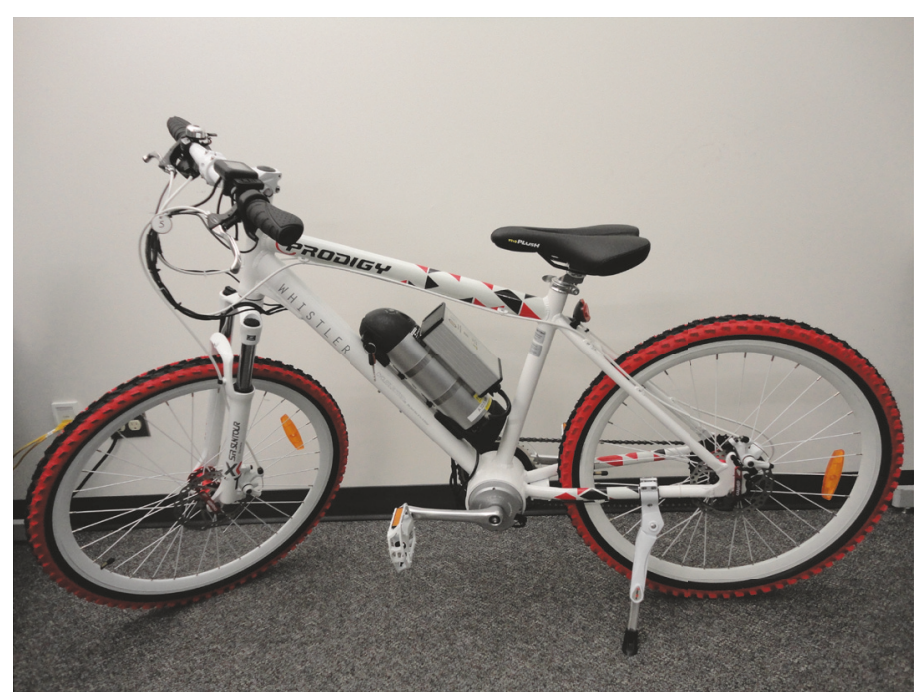

(a) An eProdigy Whistler e-bike

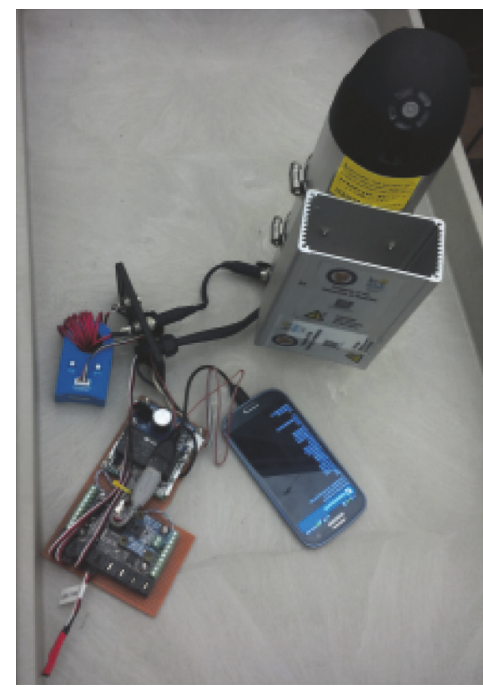

(b) A disassembled sensor kit

FIGURE 1: Illustration of the e-bikes and sensor kits used in the WeBike project.

study, Langford et al. [25], collected GPS data from a bikeshare at the University of Tennessee, Knoxville. The bikeshare had regular bikes and e-bikes. For both types of bikes, this study found similar safety issues, such as failures to come to a complete stop at red lights and stop signs and wrong-way cycling on one-way streets. Additionally, the average e-bike speed of $13.3 \mathrm{~km} / \mathrm{h}$ was found to be higher than the average regular bike speed of $10.5 \mathrm{~km} / \mathrm{h}$. Interestingly, e-bikes were found to be ridden faster on city streets, but not on other shared-use paths, suggesting that municipal by-laws should not necessarily ban e-bike use on shared-use paths.

We also found one study, Schleinitz et al. [26], which focused on the speed of e-bikes compared to regular bikes. As in the field trials we mentioned earlier, this study found that e-bikes are ridden faster, especially by cyclists under 40 years of age. This study involved 85 participants who used their own bikes or e-bikes.

In addition to field trials, there have been several surveys of e-bike owners in various parts of the world, including Australia (e.g., [27]), China (e.g., [10, 28]), Europe (see, e.g., [29]), and the United States (see, e.g., [21-23, 30]). The insights obtained from owner surveys are similar to those obtained from field trials: e-bikes are ridden faster than regular bikes and are often used for commuting and for longer trips.

Compared to existing e-bike field trials, the WeBike project spans a longer time frame (nearly three years) and therefore our dataset is less affected by "outliers" such as a single unusually cold or warm winter. Additionally, none of the previous field studies collected battery data. The WeBike dataset includes battery voltage and current measurements, which allow us to analyze charging patterns, develop a range prediction model for e-bikes [31], and compare the usage and charging patterns of e-bikes with those of electric cars [32]. On the other hand, to reduce the cost of the field trial, we do not have video footage or braking intensity data that were collected by Dozza et al.

\section{The WeBike Project}

The WeBike field trial began in the summer of 2014. After filling out questionnaires regarding their current modes of transportation and attitudes towards e-bikes, 31 out of over 100 prospective participants were selected for the field trial and each received their own e-bike to use at their discretion. Participants were selected to cover a range of current modes of transportation (automobile, public transport, and regular bicycle), occupation (16 faculty/staff members and 15 graduate students of the University of Waterloo), and gender (18 males and 13 females). The project will run until the end of 2017 and participants can keep their e-bikes afterwards for their own continued use.

The eProdigy Whistler mountain bike we chose for the study is shown in Figure 1(a). The battery provides energy to the electric motor, which is hidden in the hub between the pedals and drives the pedal axle when activated. The bike can be used in fully electric mode by pushing a throttle button located on the handlebars, or in "hybrid" mode, where the motor provides assistance whenever the cyclist is pedaling. The manufacturer's estimated battery range is $45 \mathrm{~km}$, and it takes 4 to 5 hours to recharge the battery from empty. If the battery is discharged or manually turned off, the ebike can still be pedaled like a regular bike without motor support, albeit with more effort due to its weight of about $21 \mathrm{~kg}$ including the $2.5 \mathrm{~kg}$ battery.

We mounted the box with our custom-built sensing hardware directly on top of the e-bike battery, which is detachable from the bike frame for charging. Figure 1(b) shows the battery and the disassembled sensor kit, and our project website (http://blizzard.cs.uwaterloo.ca/iss4e/webike-project) contains full technical details and assembly instructions. An Android-based Samsung Galaxy S3 smart phone acts as the central piece. We chose it for its sensors (GPS, clock, gyroscope, accelerometer, and magnetometer), built-in Wi-Fi 


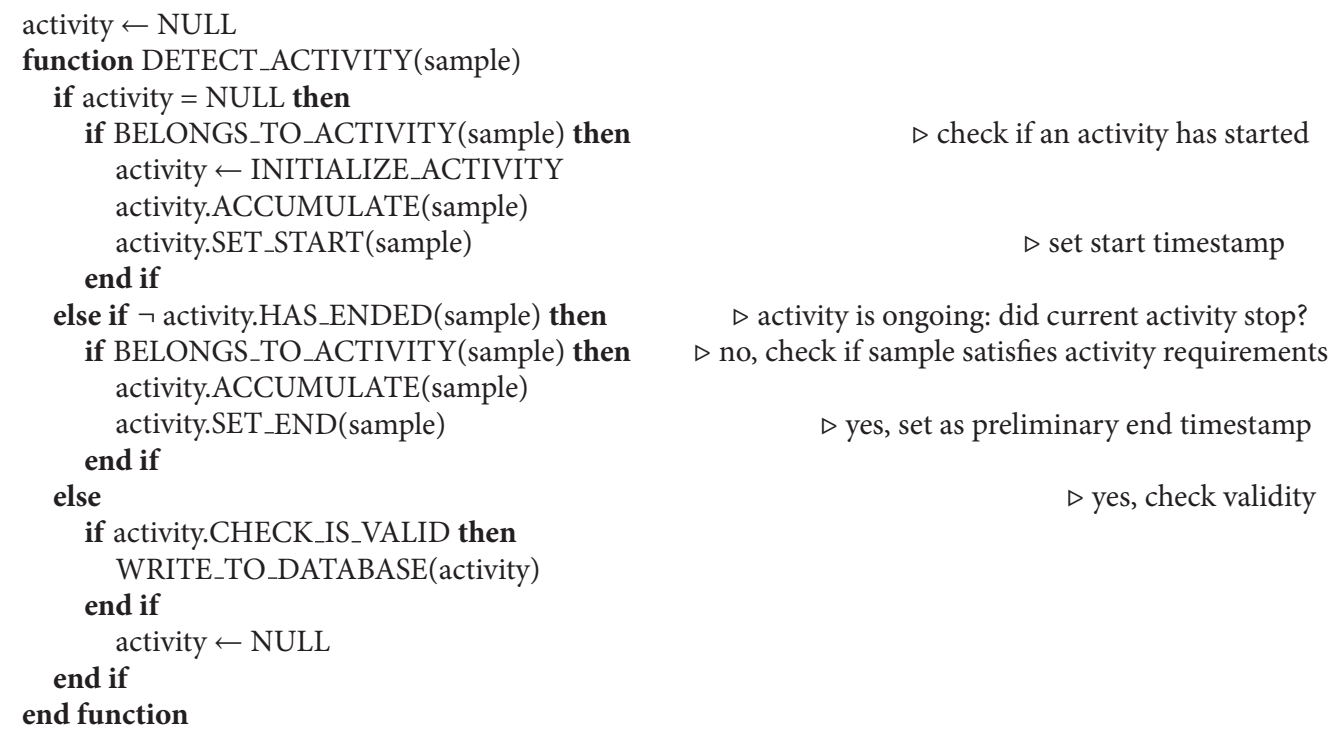

$\triangleright$ check if an activity has started

$\triangleright$ set start timestamp

$\triangleright$ activity is ongoing: did current activity stop? $\triangleright$ no, check if sample satisfies activity requirements $\triangleright$ yes, set as preliminary end timestamp $\triangleright$ yes, check validity

Algorithm 1: Activity detection.

connectivity, relatively low cost, and ease of developing custom software that is executable on the phone. Additional sensors for battery voltage, charging and discharging current, and temperature communicate with the smart phone via a Phidget board [33].

As a long-running field trial consisting of volunteers, the WeBike study aims to be as unintrusive for participants as possible. Data collection is automatic, without any input from the participants. Initially, the smart phones controlling the sensing kit were programmed to wake up and collect data for four seconds every minute. During the four seconds of activity, the phone records four data samples from each sensor and then goes back to sleep mode to minimize energy consumption (the phone battery is charged by the e-bike battery and therefore excessive energy consumption of the sensing kit would reduce the bike's range). The four-second time frame was chosen because we found it took about two seconds after wake up to obtain a GPS fix.

In the second version of the data collection platform, we programmed the smart phones to increase the sampling rate whenever activities such as movement or battery charging were detected (details in Section 4). During an activity, the phone stays awake and collects measurements from each sensor once per second. When an activity stops, the phone stays awake for five more minutes before going back to sleep mode.

For simplicity and to reduce costs, the phones do not transmit data in real time. Instead, the collected data are buffered on the phone and uploaded to our database server whenever the sensing kit comes within range of a known WiFi network (such as campus Wi-Fi or a participant's home WiFi). Each phone is associated with a unique ID so we know which bike the data are coming from.

\section{Data Processing Methodology}

In this section, we explain how we identified activities such as trips and battery charging sessions from the collected sensor measurements. Algorithm 1 shows our activity detection framework. The algorithm sequentially processes each data sample and checks for activity indicators (i.e., one or multiple sensor values exceeding a predefined threshold). If no activity is currently ongoing, a new activity is started and its starting time is recorded. If an activity is ongoing, we add the new data sample to it and advance the ending time. Finally, when we detect that an activity has ended, we check whether this is a valid activity (e.g., that it is sufficiently long) and save the accumulated data samples (and the starting and ending times) to the database. This gives us the start and end points of all trips and charging events, and we can compute further information such as trip distance or speed by examining the data samples accumulated during the activity.

In the remainder of this section, we instantiate Algorithm 1 with specific values for the functions belongs to_activity, has_ended, and check_is_valid.

4.1. Trip Identification. It might seem that trip identification is simple given that we have GPS fixes: a trip is taking place when there is movement. However, GPS data turned out to be too imprecise for trip detection: even parked bikes appeared to be "moving" because consecutive GPS readings could be several hundred meters apart. Furthermore, it may take several minutes to obtain an initial GPS satellite fix, leading to loss of information about the beginning of every trip.

Instead of GPS, we use the accelerometer, gyroscope, and discharge current to detect trips. The details are as follows.

belongs_to_trip: a sample is said to belong to a trip if the absolute values of either the accelerometer, gyroscope, or discharge current sensor exceed a certain 
threshold. These thresholds were set by examining sensor readings of 225 trips for which we knew the true start and end times.

has_ended: it is true if 5 minutes has passed since the preliminary end of the trip. This means that a trip with a break of under five minutes will not be divided into two shorter trips and accounts for stopping at traffic lights.

check_is_valid: trips shorter than 3 minutes are discarded.

Out of the 225 trips for which we knew the precise start and end times, the algorithm missed five trips that were under three minutes long and found two trips that did not actually take place. We also experimented with lower thresholds for minimum trip length and were able to capture the five short trips at the expense of identifying many more spurious trips. In the end, we kept the minimum trip duration threshold at 3 minutes. Furthermore, when comparing trip durations computed by our algorithm with the true durations of the 225 known trips, we found that our results were within five percent of the true durations.

4.2. Charge Cycle Identification. To detect charging, the WeBike dataset contains readings from a Hall-effect based current transducer that measures the current traveling through the sensor box when it is connected in series between the AC charger and the battery.

We instantiate the generic algorithm using the following values:

belongs_to_trip: charging starts when the charge current sensor exceeds a certain threshold, which eliminates false positives due to sensor noise.

has_ended: it is true if 5 minutes has passed since the preliminary end of the charge cycle.

check_is_valid: charge cycles that take less than 5 minutes or contain fewer than 5 samples are discarded. Recall that it takes several hours to fully charge a battery, so a very short charge cycle is a false positive, typically due to a loose contact between the charger and the battery.

Using this algorithm, we found all the true charge cycles for which we had ground truth information.

\section{Usage Data Analysis}

This section presents our analysis of e-bike trips, focusing on trip start time, duration, trips per month, and average speed. For behaviour comparison, we split the dataset into the staff/faculty and students subgroups. The data distributions we analyze are not normally distributed; thus, to identify significant deviations between groups, we use the nonparametric Wilcoxon rank-sum test with a 95\% confidence level.

5.1. Trip Statistics. As Table 2 shows, we detected over 6000 trips. The normalized numbers (per participant in each group) reveal that students use their e-bikes significantly
TABLE 2: WeBike trip statistics.

\begin{tabular}{lccc}
\hline & Total & $\begin{array}{c}\text { Staff/faculty } \\
\text { members }\end{array}$ & Students \\
\hline $\begin{array}{l}\text { Number of trips } \\
\begin{array}{l}\text { Average number of trips per } \\
\text { participant }\end{array}\end{array}$ & 6048 & 2567 & 3481 \\
$\begin{array}{l}\text { Average trip duration per } \\
\text { participant (min) }\end{array}$ & 11.3 & 197.5 & 290.1 \\
\hline
\end{tabular}

more often than staff/faculty members, possibly because few Waterloo students own cars, so they are restricted to either public transit or biking. The average trip duration will be discussed in more detail below.

Trips per Month. Figure 2(a) shows the distribution of trips over the course of a year. No significant differences for the occupational breakdown exist, so we omit those charts for brevity. The effect of the cold Canadian winter in Waterloo can clearly be seen by a dwindling trip probability starting in October, then sharply dropping in December, and staying low until April. However, some participants still use their e-bikes all year round. The dip in August is likely due to vacations during the university's break between terms.

Start Times. Figure 2(b) plots the distribution of trip start times over the hour of day. This distribution shows two prominent peaks, suggesting that participants commute to the university in the morning between $8 \mathrm{am}$ and $10 \mathrm{am}$ and return home between $4 \mathrm{pm}$ and $6 \mathrm{pm}$. During work hours between those peaks, the distribution is quite even and it tapers out in the evening after the commute, until the probability for trips between $11 \mathrm{pm}$ and 7 am becomes almost negligible. This leads to the conclusion that e-bikes are less likely to be used for evening activities and they are obviously not used while people are sleeping. The split between staff/faculty members and students in Figure 2(c) shows a slight shift in commuting times, with the student peak about an hour behind the staff/faculty peak. Furthermore, students tend to use their bikes more in the evening as well.

Trip Duration. Figure 3(a) shows the frequency of trip durations (in minutes) for all participants, including a cumulative plot summing up to the total of 6048 trips. As discussed in Section 4.1, we count trips if they are longer than three minutes. Therefore, the first bar only includes trips of length three to five minutes. However, for readability, we let the bar chart split by occupation in Figure 3(b) start from 0, although the same restriction applies. The majority of e-bike trips take between 7 and 15 minutes with an average of 11.3 minutes, while only a couple of trips took more than 40 minutes.

As evidenced by the average trip duration in Table 2, staff and faculty members in our study are more likely to use their bikes for longer trips than students, while the latter group is more likely ( $p$ value of $3.5 \cdot 10^{-8}$ ) to go on trips of length between three and 10 minutes. Given that a majority of trips are for commuting, this could be partially explained by the students living closer to the university campus. Still, 


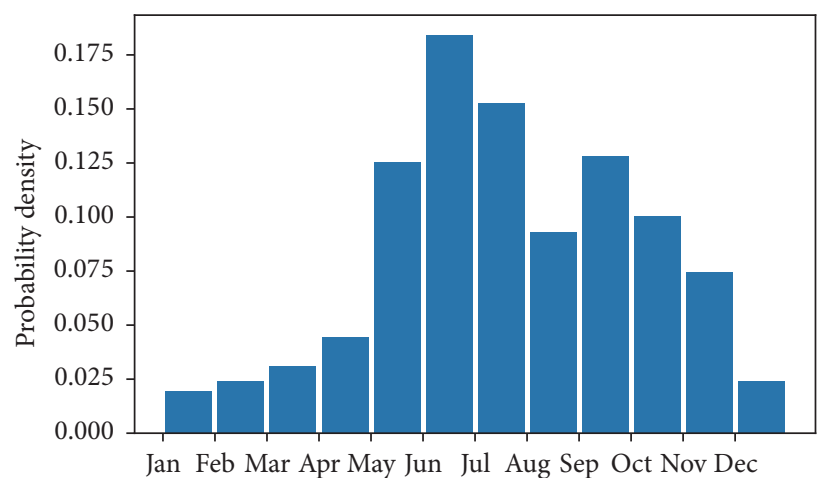

All participants

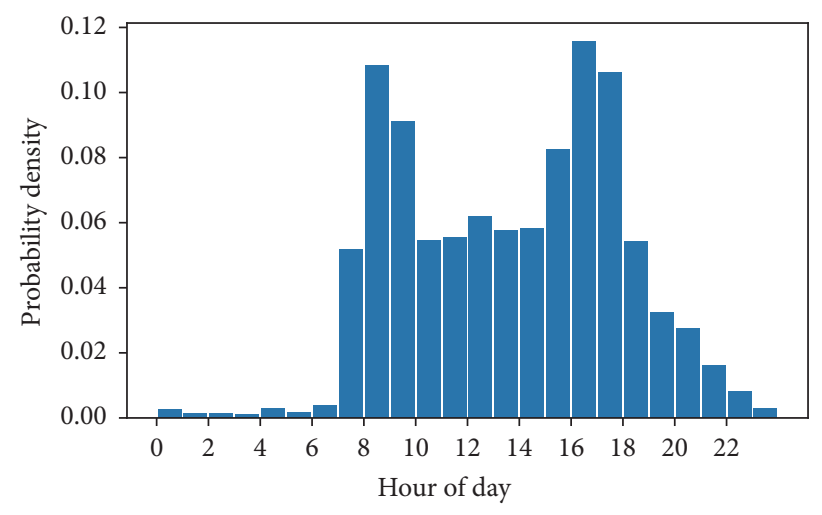

All participants

(a)

(b)

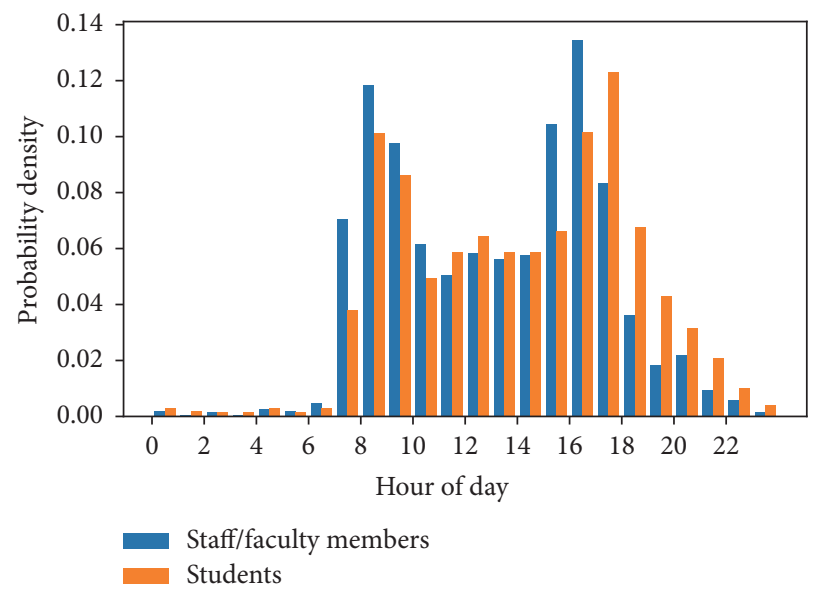

(c)

Figure 2: Probability distribution of a trip start (a) on a month-of-year scale, (b) on an hour-of-day scale, and (c) on an hour-of-day scale split by occupation.

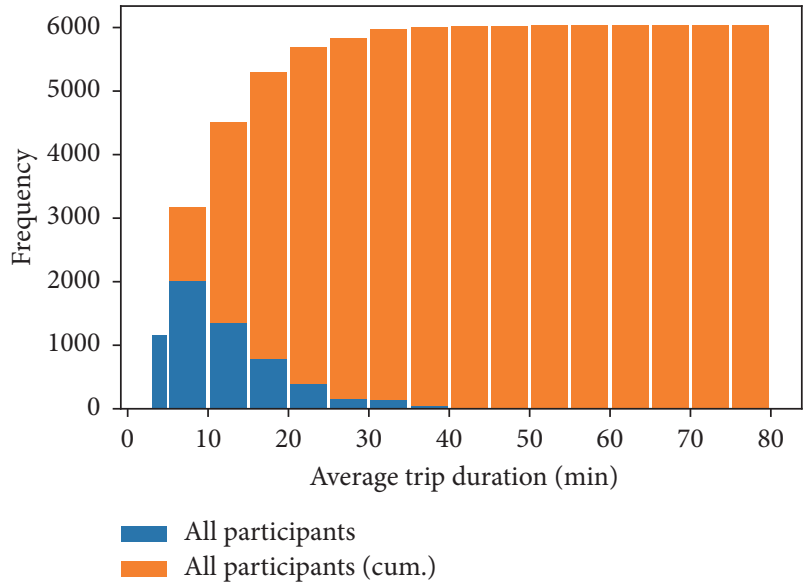

(a)

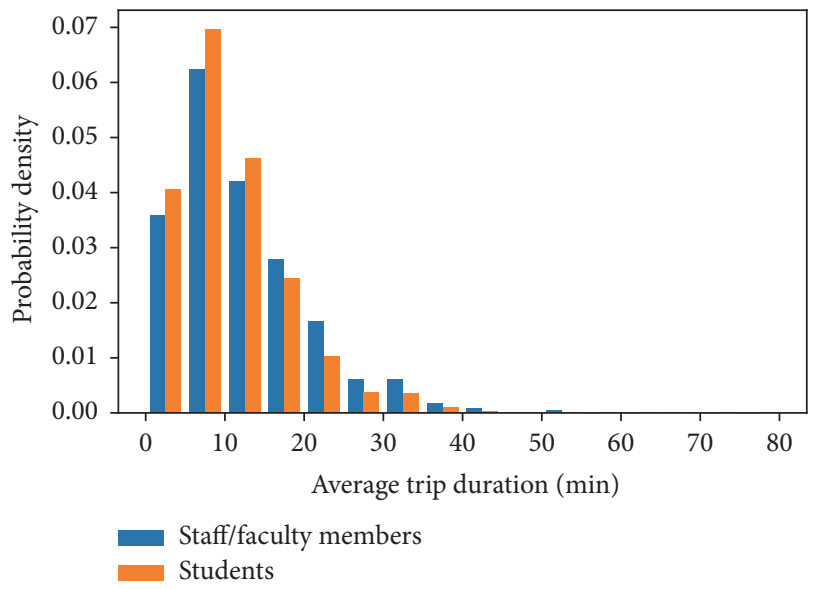

(b)

FIGURE 3: (a) Trip duration (cumulative) frequency; (b) trip duration probability distribution split by occupation. All plots are shown on a minute scale. 


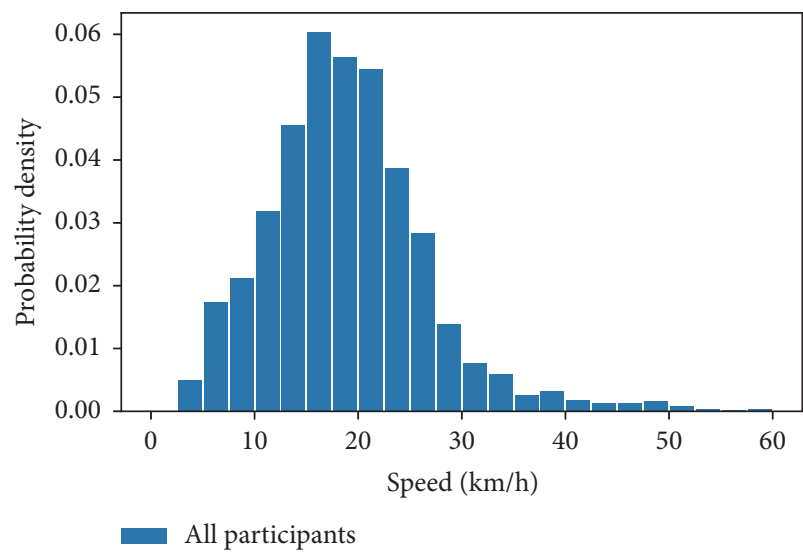

(a)

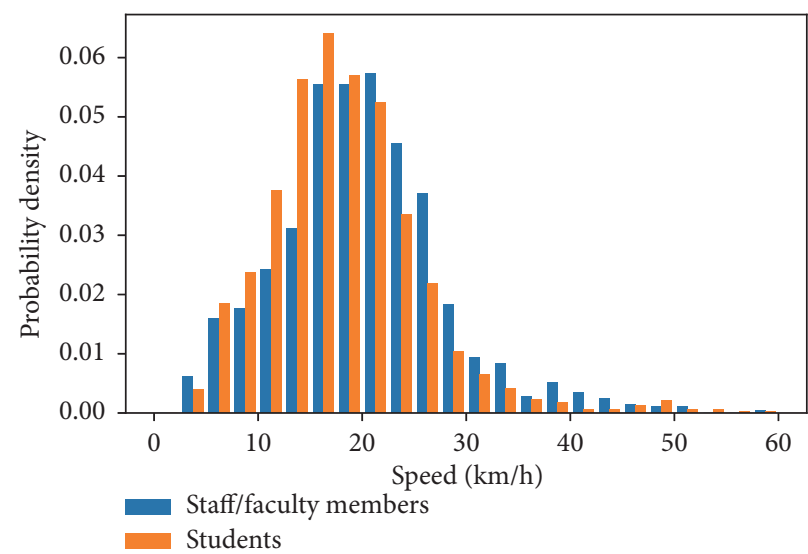

(b)

FIGURE 4: Probability distribution of the average trip speed in $\mathrm{km} / \mathrm{h}$ (a) for all participants, (b) split by occupation.

both groups show the highest probability for trips of a length between five and 10 minutes.

Average Speed per Trip. We calculated the average speed by computing the distance and time between consecutive GPS fixes during each single trip. We are interested in the actual speed while participants ride their bikes, so we exclude those trip sections where the GPS signal does not change significantly; that is, the bike rider waits at a traffic light or an intersection. We found a cut-off of segments below $3 \mathrm{~km} / \mathrm{h}$ to be a good threshold. This corresponds to a slow strolling speed and can therefore be safely assumed to not have resulted from regular riding; at most it occurred just after starting or just before stopping. Therefore the threshold is low enough to leave most of the trip speed information intact while removing temporary stops.

As a consequence of measuring location at discrete times, our results present a lower bound on the actual average speed, as the true trip route must follow roads and pathways and can therefore deviate from the direct (shortest) path between two GPS fixes. Additionally, the GPS signal can be inaccurate. This is evidenced by the right tail of the distribution in Figure 4(a) at high speeds. As per the traffic law in the province of Ontario, Canada, e-bike motor support must stop above $32 \mathrm{~km} / \mathrm{h}$. While it is possible to achieve an average speed above that limit (e.g., if a trip includes a long downhill slope), it is more probable that the GPS fix does not reflect the accurate location at least for some of those high-speed trips or the e-bike was taken on a bus. Unfortunately, for the data up to the time of this analysis, we have no measurement for GPS accuracy in place. However, judging from the low probability for the right tail of the histogram in Figure 4(a), this is not a major distribution-skewing concern. As the plot for all participants shows, most trips have an average speed of $15-23 \mathrm{~km} / \mathrm{h}$ (while in motion) with a mean of $18.9 \mathrm{~km} / \mathrm{h}$. The breakdown by occupation in Figure 4(b) amounts to a $2.0 \mathrm{~km} / \mathrm{h}$ higher mean of average trip speed of staff/faculty members ( $p$ value $2.3 \cdot 10^{-14}$ ).
TABLE 3: Battery charging statistics.

\begin{tabular}{lccc}
\hline & Total & $\begin{array}{c}\text { Staff/faculty } \\
\text { members }\end{array}$ & Students \\
\hline $\begin{array}{l}\text { Charging events } \\
\text { Average charging events per }\end{array}$ & 1049 & 522 & 527 \\
participant & 42.0 & 40.2 & 44.0 \\
Average trips per charge & 5.8 & 4.9 & 6.6 \\
\hline
\end{tabular}

5.2. Battery Charging Statistics. Observing behavioural patterns of battery charging events helps to understand if participants feel range anxiety and how they incorporate ebikes in their daily schedules. In this section, we analyze the hour of day and state of charge when a charge cycle begins. With the algorithm described in Section 4.2, we detected about 1000 charge cycles as shown in Table 3 . Students, on average, take almost two trips more between charges than staff/faculty members; this possibly consists of one round trip.

Charging Start Times. Figure 5(a) presents the probability distribution for the beginning of a charge cycle across all participants. The most prominent peak between $4 \mathrm{pm}$ and $7 \mathrm{pm}$ coincides with the commuting peak in the trip distribution chart. Thus, participants tend to charge their batteries directly when they return home. Further comparison of those distributions in the evening shows that the charge cycle distribution's tail declines more slowly but has a sharper drop around midnight. This indicates that those who did not charge their batteries right after coming home are likely to plug them in later in the evening, possibly before going to bed. As expected, very few charge cycles start between midnight and $5 \mathrm{am}$.

The morning commuter peak between 8 am and $10 \mathrm{am}$ is not as prominent as in the evening, but still visible. Since the charging distribution follows the trip distribution relatively closely even during work hours, we conclude that many participants either take their charger with them or have a charger permanently at work. Interestingly, the rising edge 


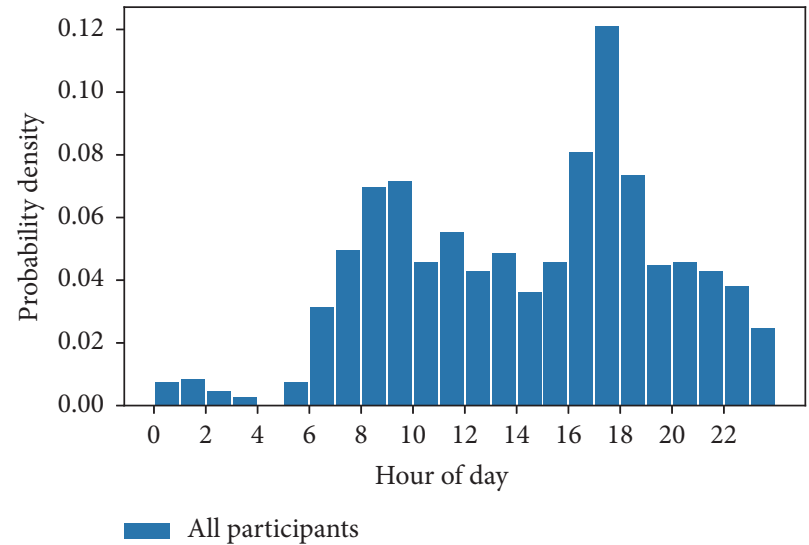

(a)

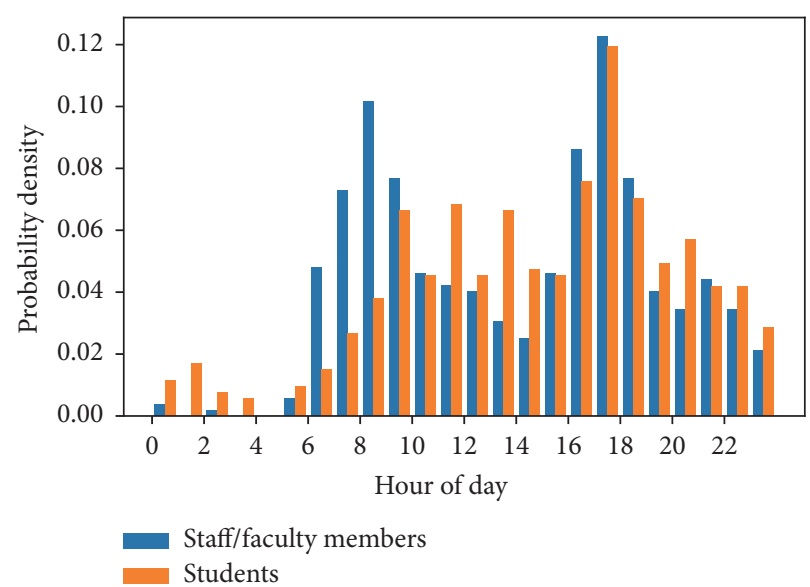

(b)

FIgURE 5: Probability distribution of the start of a charge cycle on an hour-of-day scale (a) for all participants, (b) split by occupation.

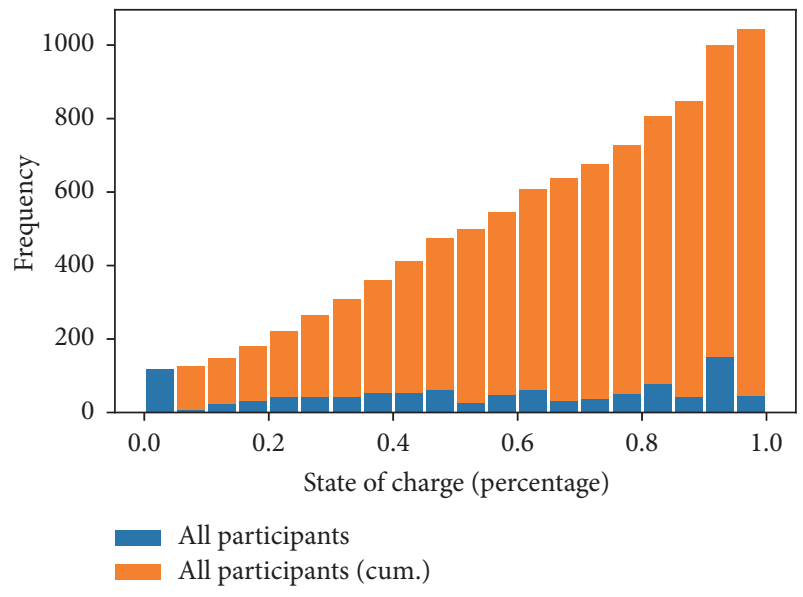

(a)

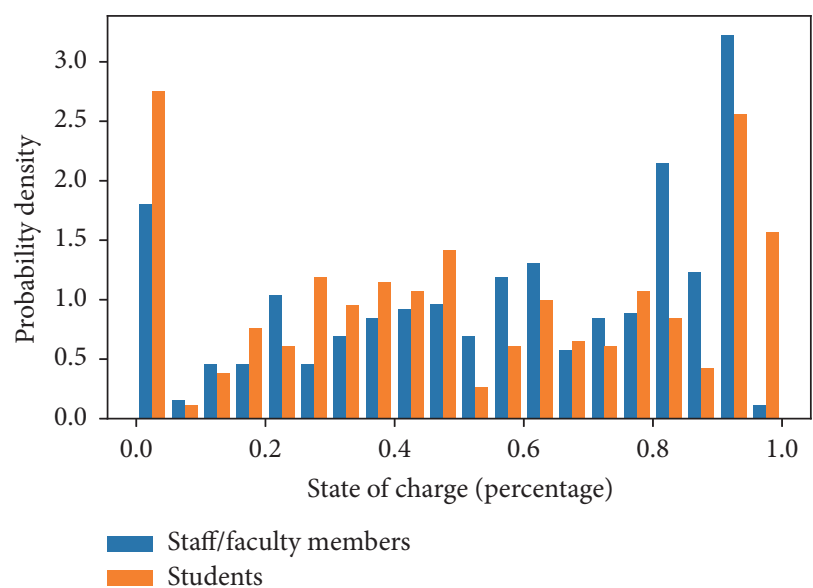

(b)

FIGURE 6: (a) Start of a charge cycle (cumulative) frequency over state of charge; (b) probability distribution of the start of a charge cycle over state of charge, split by occupation.

in the morning starting between 5 am and 6 am precedes the commuting peak, meaning some participants charged their batteries in the time between waking up and going to work. As Figure 5(b) for the occupational split shows, this rising edge is especially prevalent in the staff/faculty group. Participants in this group are also the main contributors to the morning peak after the commute to work. These findings are statistically significant, with a $p$ value of 0.01 . Figure 5(b) also shows that students in the study were more likely to start charging after 8 pm until late at night.

State of Charge at the Beginning of a Charge Cycle. It was impossible to obtain the state of charge of the battery directly and the installed current sensor proved to be too imprecise to use a Coulomb counting method. Instead, we measured the battery's voltage and temperature and used the reversible discharge curves in the battery's spec sheet to convert those metrics into the state of charge [34]. On a scale from 0 , meaning an empty battery, to 1 , meaning a fully charged one,
Figure 6(a) presents the amount of charge cycle starts for a given state of charge, as well as the cumulative value. At the beginning of the study, participants were asked to recharge their batteries as often as possible to slow the degradation of the health of the batteries. This explains the nonzero value for charges between $95 \%$ and $100 \%$, as well as the high peak in the 90-95\% interval, which probably coincides with the state of the battery after one trip for most participants. Three smaller peaks at $80-85 \%, 60-65 \%$, and $45-50 \%$, with increasingly longer left-handed tails, can be noticed. Judging from their distances to each other, these could be attributed to the second, fourth, and sixth trips.

A surprisingly large number of participants charged their batteries when they were empty, although they were specifically told not to wait that long. The decline of charging probability from $20 \%$ state of charge to just before the battery drains completely suggests that the high peak at $0 \%$ charge does not stem from participants who usually let their batteries run low and occasionally drain them completely. We propose 


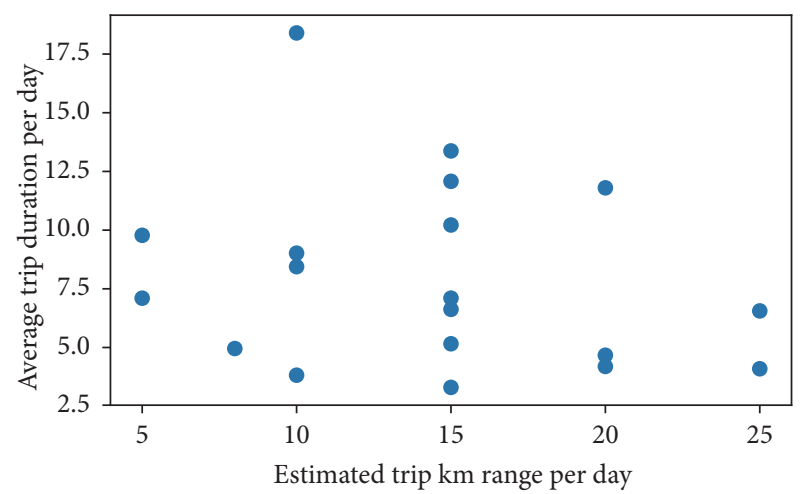

(a)

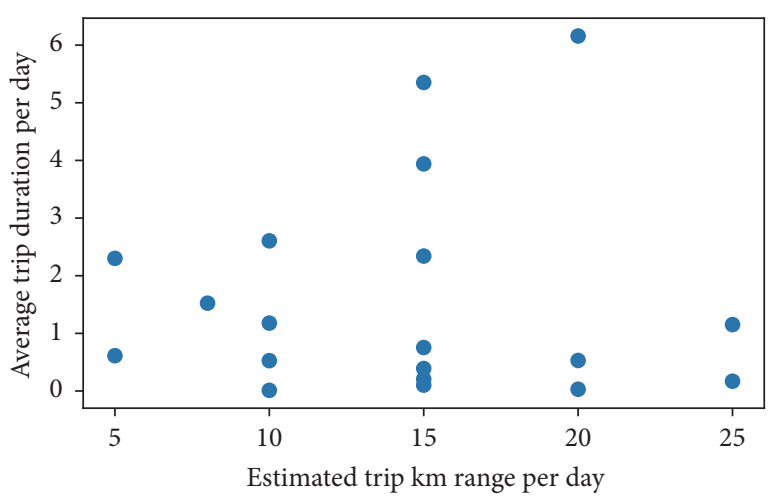

(b)

Figure 7: Actual riding behaviour compared to the estimated behaviour. Both figures show the average duration of a trip. (a) plots trips in summer (May-October), while (b) shows trips in winter (November to April).

two possible explanations for this contrast between charging from empty compared to charging from almost empty. First, some participants might habitually charge their battery only after they drained it in use. Second, the attached sensor kit slowly drains the battery completely, especially when stored for the winter. Despite the highest peaks being at empty or (almost) full, the relative evenness of the rest of the plot leads to the conclusion that our participants did not feel range anxiety. This makes sense because, similar to hybrid cars, riders can continue pedaling their e-bikes with an empty battery.

Figure 6(b) shows that students were more likely to let their batteries drain completely and have a higher probability to charge in the $15-45 \%$ range, while staff and faculty members are more likely to charge above $70 \%$ ( $p$ value of 0.049 ). Interestingly, charging events at above $95 \%$ are almost exclusively from students.

\section{Survey Analysis}

We now analyze the results of the three participant surveys. The first survey was taken by 172 prospective participants in early summer 2014 before the field trial started, the second by 24 of the 31 selected participants in fall 2015, and the third again by 24 participants in fall 2016. After eliminating invalid responses, we have 11 participants who completed all three surveys and two participants who only completed the first and third survey.

All three surveys asked the participants to rate various modes of transportation on several criteria such as comfort and independence, as detailed below. Additionally, participants were asked about their expected riding behaviour in the survey before the trial or to estimate their current riding behaviour in the yearly surveys thereafter.

We start by comparing anticipated with actual riding behaviour and then proceed to sentiment analysis.

6.1. Anticipated versus Actual Riding. In the initial survey before the field trial, participants were asked to estimate the number of kilometres they would ride their e-bike on an average day in summer (May to October) and winter (November to April). We correlate these estimates with the actual recorded trip data. Since the recorded GPS data is spotty and often missing for the first couple of minutes of a trip, we use trip durations instead. There is a strong correlation between actual covered distance and trip duration if we reasonably assume that, for a given participant, the usual trip speed does not vary greatly. Therefore, even if trip duration is not as suitable as the (unavailable) correct recorded trip distance, it should still be possible to judge the correlation between the estimated riding behaviour and the actual recorded one. For a fair judgment we only consider work days in this analysis.

Summer Riding. Figure 7(a) shows a scatter plot with the anticipated distance per day on the $x$-axis and the average number of minutes actually ridden per day on the $y$-axis. Each data point represents one participant. There is no obvious trend as evidenced by a Pearson correlation coefficient of -0.23 with a $p$ value of 0.34 . However, participants grossly overestimated their e-bike usage, assuming an average speed below $30 \mathrm{~km} / \mathrm{h}$.

Winter Riding. If participants with an average trip duration of less than one minute are excluded from the analysis, then there is a linear relationship between estimated and actual winter riding. However, this is a rather arbitrary threshold, so we offer the same general conclusion as for summer trips: there is no correlation between anticipated accumulated trip distance and actual trip duration per week (Pearson correlation coefficient of 0.02 with a $p$ value of 0.93 ). In comparison to the summer months, the average trip duration is drastically reduced. Given that the average riding speed should be lower due to worse road conditions (snow or rain puddles in the bike lanes), participants overestimated their riding frequency in the winter months even more.

6.2. Sentiment Analysis. Each survey asked the participants to rate how important each of the following ten aspects of transportation modes is to them: 


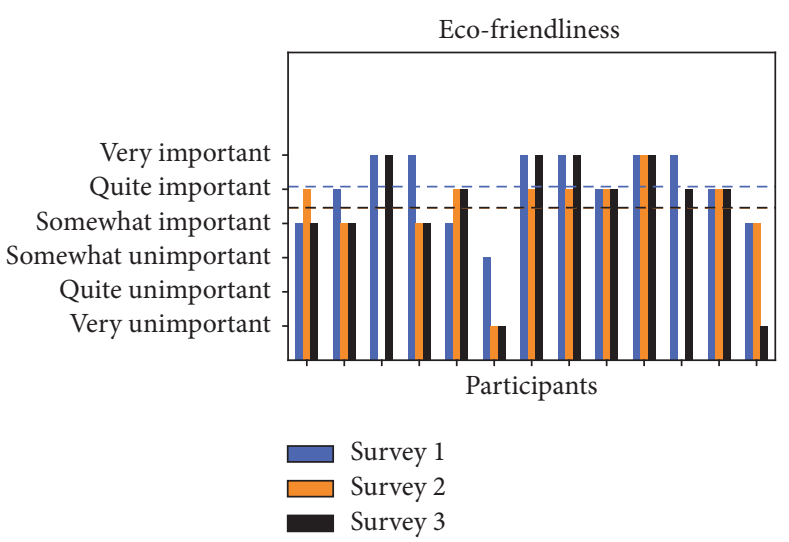

(a)
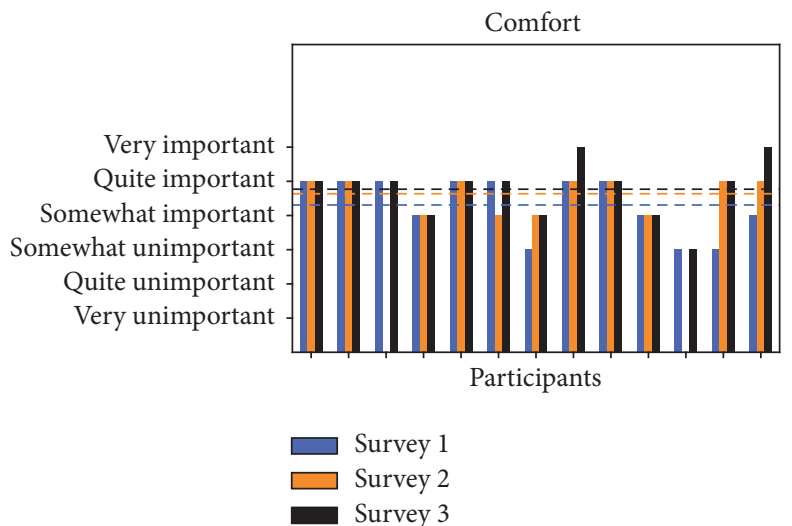

(c)

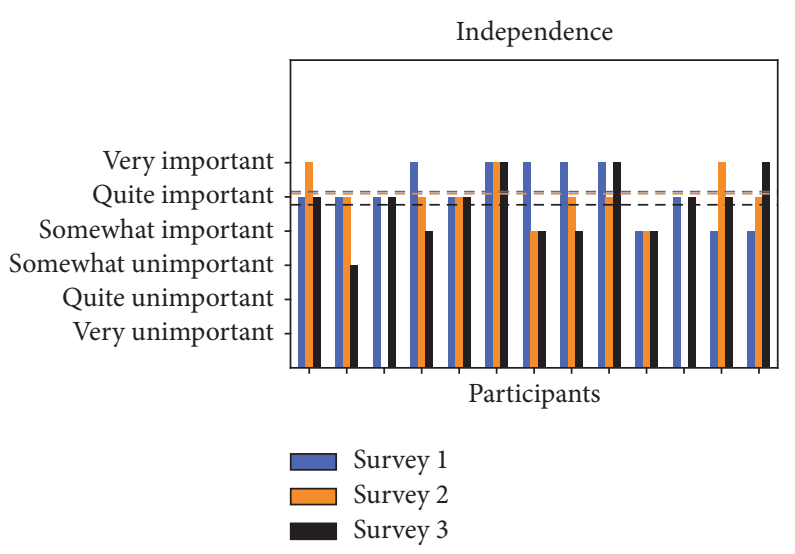

(e)

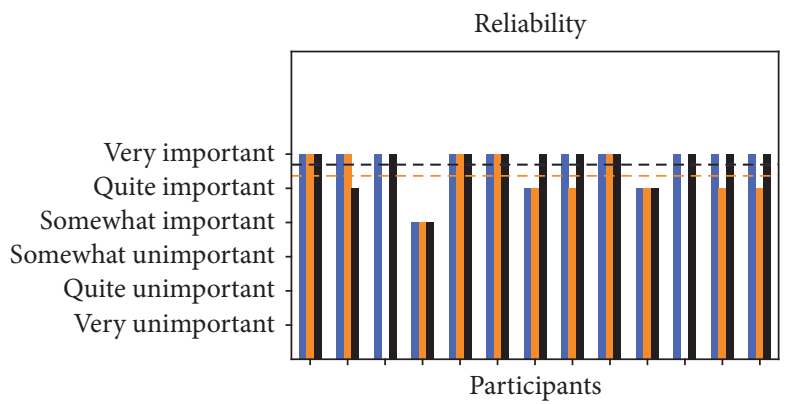

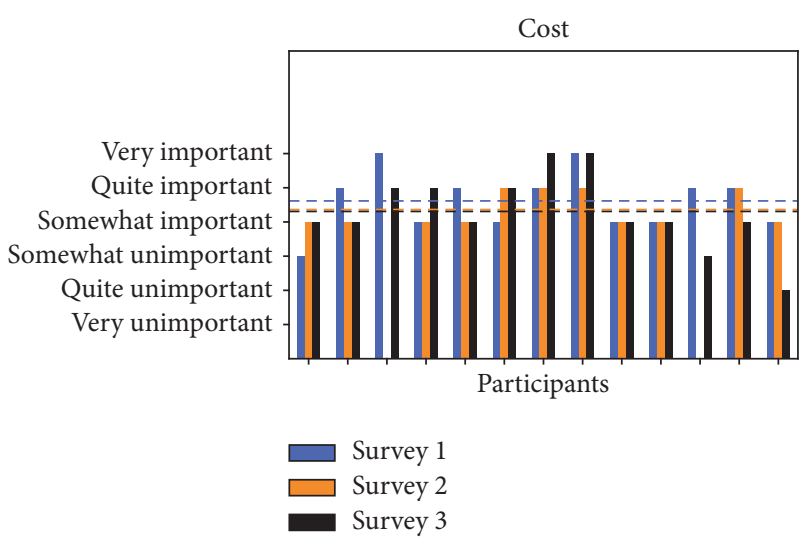

(b)

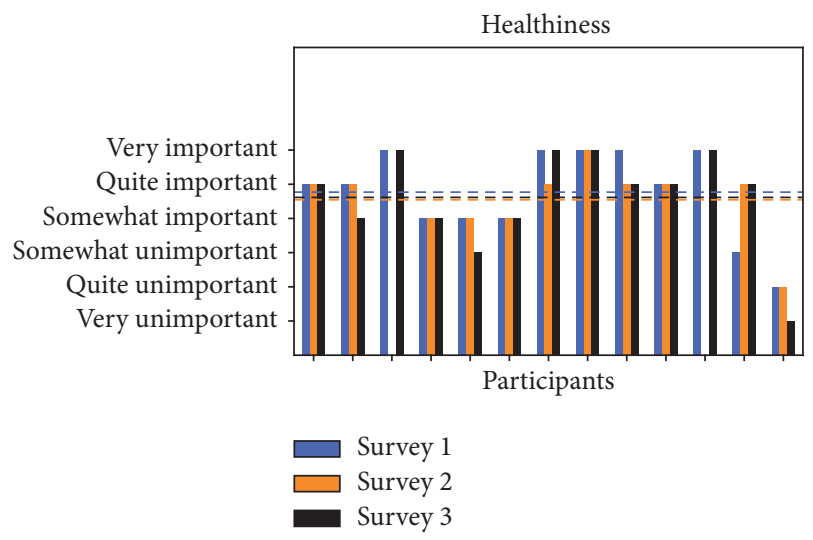

(d)

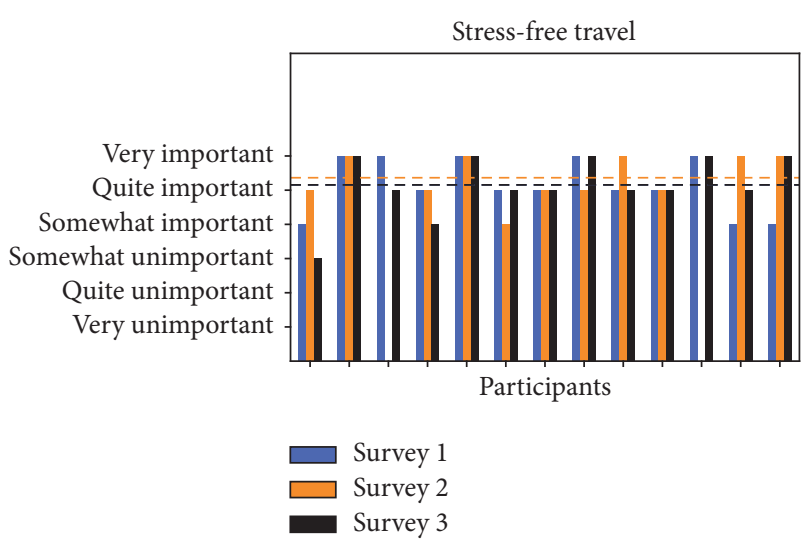

(f)

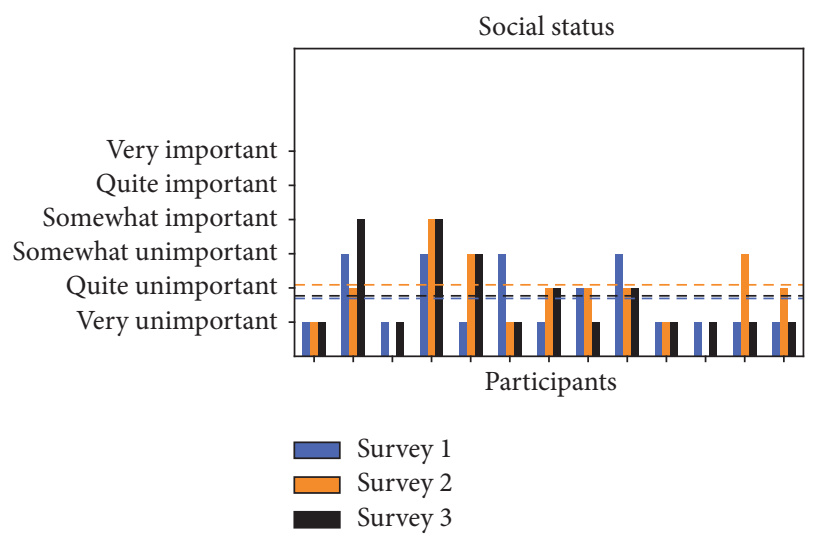

(h)

Figure 8: Continued. 


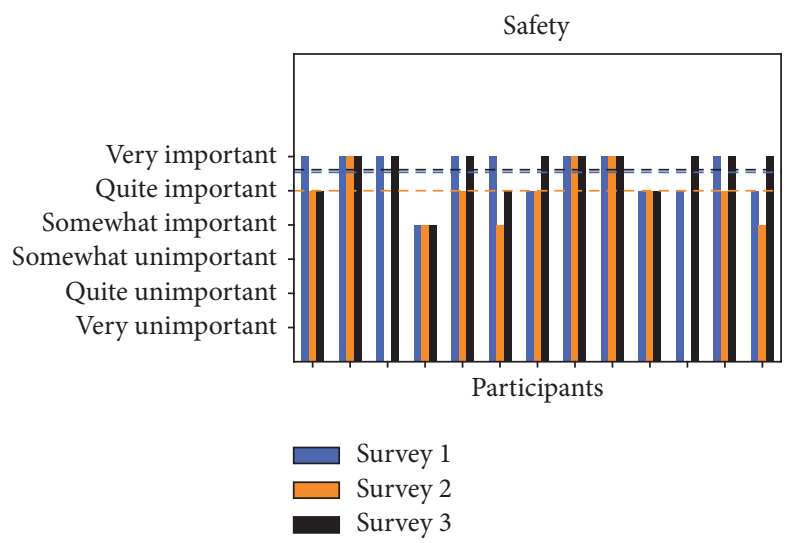

(i)
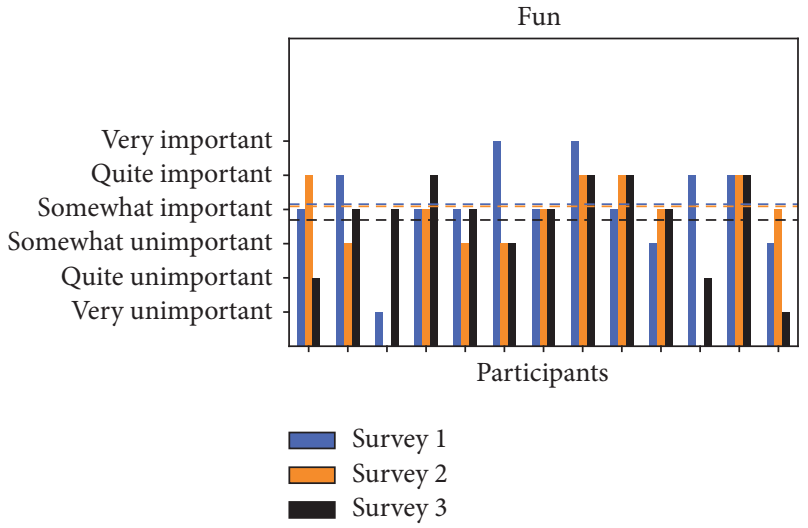

(j)

FIGURE 8: Evaluation of the importance of 10 different aspects of modes of transportation across three surveys, broken down by participant. Dashed lines show the mean of the responses of the survey in the respective color.

Independence. How much independence does a given mode of transportation provide?

Stress-Free Travel. How stress-free is the travel with that mode?

\section{High Cost. How expensive is it?}

Social Status. How well does it fit with the participant's perceived social status?

Fun. How much fun does it provide?

Eco-Friendliness. How environmentally friendly is it?

Reliability. How reliable is it?

Comfort. How much comfort does it provide?

Safety. How safe is it?

Healthiness. How healthy is it?

Next, each survey asked the participants to rate five modes of transportation (car, regular bike, e-bike, public transit, and walking) in terms of the above ten aspects.

Aspect Importance. We begin by analyzing the importance of the above ten aspects of transportation to our participants; the full results are shown in Figure 8. The responses of 13 participants who completed at least the first and last survey are depicted as bars ranging from very important to very unimportant; each group of three bars corresponds to the first, second, and third survey, respectively. Dashed lines mark the mean over all responses for the survey of the same color. There are no obvious trends, meaning that the participants' opinions about the ten aspects of transportation modes have not changed significantly throughout the WeBike field trial. Notably, our participants value independence, stressfree travel, reliability, and safety of a mode of transportation, while social status is not important.

Comparison of Modes of Transportation. Figure 9 shows the mean and standard deviation, across all participants, of how each aspect of each mode of transportation was rated. Again, there are no significant changes in the ratings from the first to the last survey.

In terms of independence, cars were unsurprisingly rated highest followed by bikes, e-bikes, walking, and public transit. Walking is the most stress-free mode of transportation, followed by bikes and e-bikes, and then cars and public transit. On reliability, participants ranked cars, bikes, and ebikes very close behind walking, although e-bikes are slightly trailing behind. Participants see public transit and walking as the safest modes of transportation, with the other modes on par with each other. Looking at environmental friendliness, cars take last place by far. Walking obviously was ranked first and then came in regular bikes, followed by e-bikes and public transit.

Overall, participants ranked walking best by far. E-bikes scored worse than regular bikes, which were deemed more healthy and eco-friendly and less expensive. On the other hand, e-bikes beat cars in all of those aspects, although cars are seen as more independent and more comfortable.

\section{Discussion and Conclusions}

In this paper, we analyzed e-bike usage and battery charging data from the WeBike field trial. By design, e-bikes were meant to be used for commuting, potentially replacing the use of cars or public transit. Our analysis of over 150 gigabytes of data spanning nearly three years leads to the following main insights.

(i) Most trips lasted less than 20 minutes and took place during spring, summer, and fall, although some participants did ride their bikes all year.

(ii) On average, students made more e-bike trips than faculty and staff members, were more likely to ride in the evening, and had lower average speed trips.

(iii) We did not see evidence of range anxiety, in that a significant fraction of charging events happened at a low state of charge. Furthermore, participants appeared to charge their battery shortly after coming 


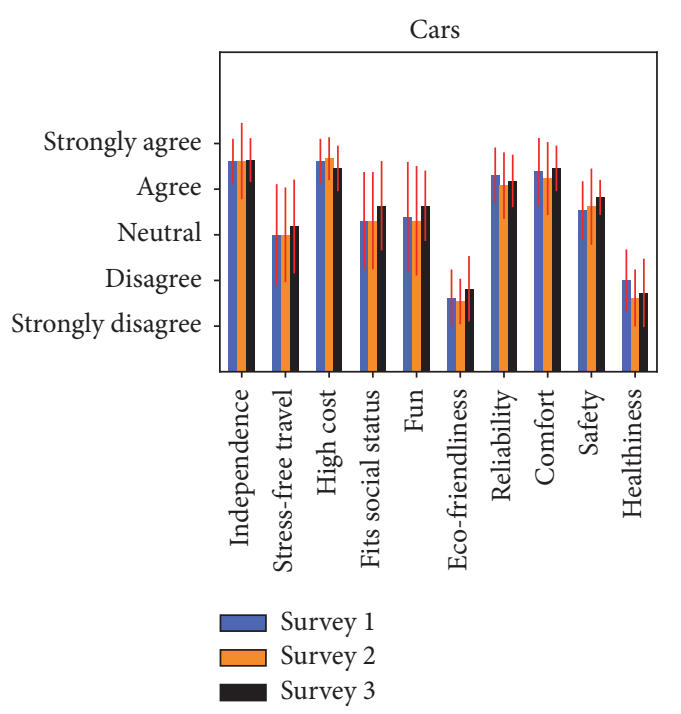

(a)

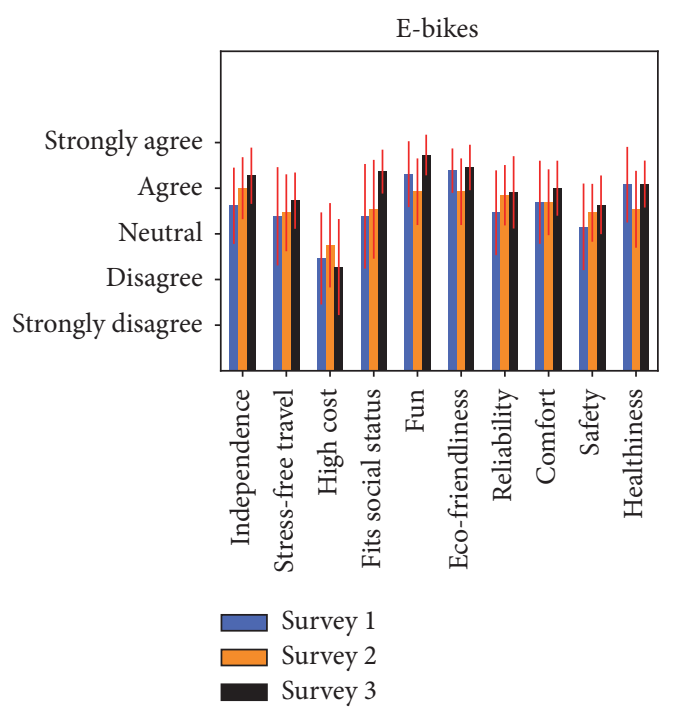

(c)

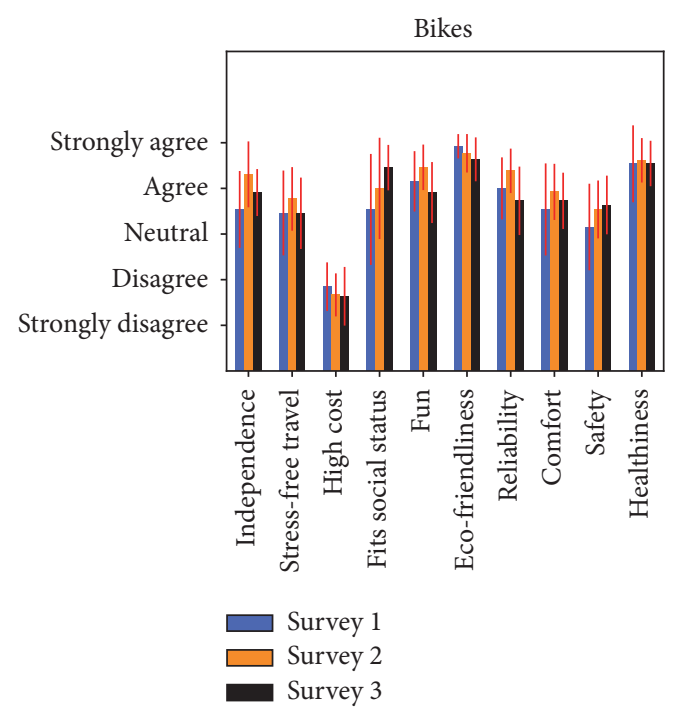

(b)

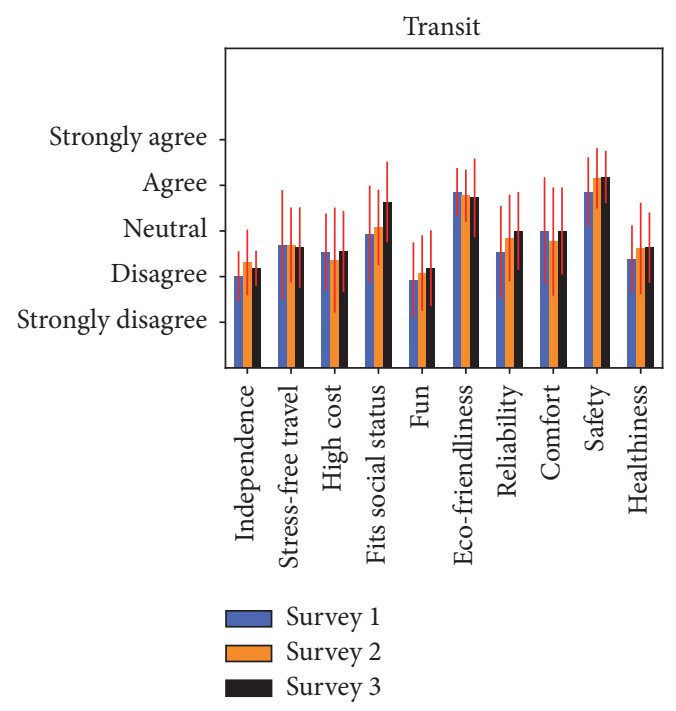

(d)

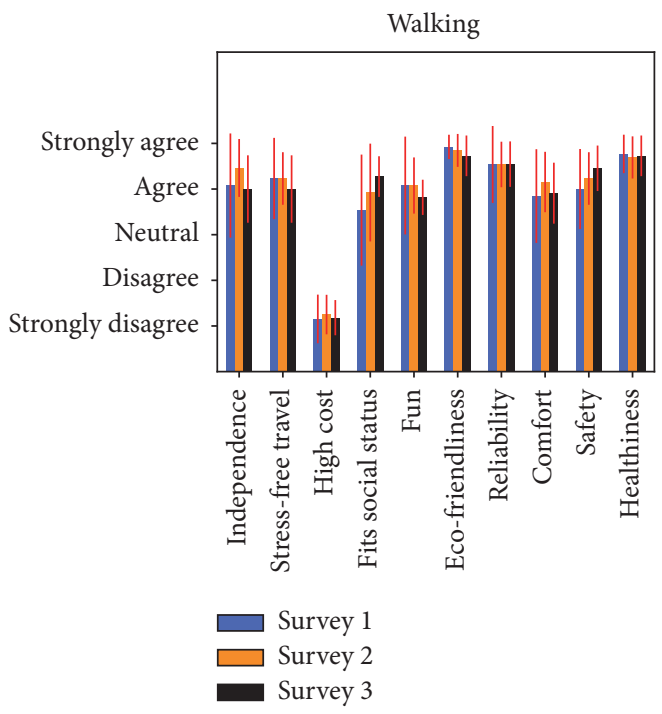

(e)

FIGURE 9: Evaluation of multiple modes of transportation on 10 different aspects across three surveys. For every survey, the mean responses including red error bars are shown. 
to work in the morning and returning home in the afternoon.

(iv) We did not find much correlation between the participants' actual e-bike usage and their anticipated usage (as estimated by them in the pretrial survey).

(v) Participation in the WeBike field trial did not significantly change participants' sentiments towards various modes of transportation. Furthermore, ebikes were rated lower than regular bikes on independence, reliability, stress-free travel, and environmental friendliness. However, e-bikes were rated higher than cars on all aspects except independence and comfort.

Some of our results are similar to those of existing surveys and field trials: others have also found that e-bikes tend to be used for commuting. Some surveys reported longer trip times than ours (e.g., [10]) but this may be due to the relatively small size of the city of Waterloo.

Our results also reveal new insight into the usage patterns of e-bikes:

(i) The lack of correlation between anticipated and actual usage suggests that our participants, and prospective buyers in general, may not be familiar with the capabilities of e-bikes. Thus, manufacturers may need to educate their prospective customers.

(ii) Range anxiety does not appear to be a problem for ebikes with a relatively light "regular bike" form factor. Thus, range anxiety does not appear to be a barrier to adoption, unlike the situation for electric cars. However, further research should be done for scooterlike e-bikes which are much heavier.

(iii) Student participants made more trips per person than faculty and staff members, suggesting that students used e-bikes for more than commuting. This also suggests that e-bikes have not fully displaced car travel for participants such as faculty/staff members who (unlike students) own cars.

(iv) Participants who are staff or faculty members were faster than students, on average. Combined with the observation that students were more likely to use their e-bikes for other purposes besides commuting, this suggests that e-bike commuters appreciate the speed of e-bikes but also brings up commuter safety concerns.

(v) We found that e-bike use does not cease in the winter months. Hence, e-bike manufacturers in countries with winter weather should consider offering built-in fenders and lights for safer winter cycling.

(vi) Since our participants continued to rate regular bikes higher than e-bikes, even after using e-bikes for a sustained period of time, this suggests that perhaps ebikes should not be marketed directly against regular bikes. Instead, e-bike retailers may want to target populations such as seniors who could benefit from the unique aspects of e-bikes such as the ability to be ridden with less physical effort.
Our long-term objective is to use big data to support public policy development in the area of e-bikes, to understand whether and how e-bikes can become a significant component of a sustainable urban-transportation mix, and to understand whether e-bikes can improve public health. To answer these questions, we plan to run a follow-up field trial with more e-bikes and more participants from various social and demographic groups.

\section{Conflicts of Interest}

The authors declare that there are no conflicts of interest regarding the publication of this article.

\section{Acknowledgments}

The authors would like to acknowledge the contributions from many WeBike project team members over the years, including Tommy Carpenter, Simon Fink, Lukas Gebhard, Fiodar Kazhamiaka, Mykhailo Kazhamiaka, Milad Khaki, Costin Ograda-Bratu, and Rayman Preet Singh. The survey was designed by Professor Tobias Schroeder at the Potsdam Institute for Applied Science. Funding for this research was provided by Cisco Systems and the Natural Science and Engineering Research Council of Canada (NSERC).

\section{References}

[1] H. Timmons, Consider the e-bike: Can 200 million Chinese be wrong?, 2017, http://tinyurl.com/q8dqjcs.

[2] C. R. Cherry, J. X. Weinert, and Y. Xinmiao, "Comparative environmental impacts of electric bikes in China," Transportation Research D: Transport and Environment, vol. 14, no. 5, pp. 281290, 2009.

[3] F. Jin, J. Ding, J. Wang, D. Liu, and C. Wang, "Transportation development transition in China," Chinese Geographical Science, vol. 22, no. 3, pp. 319-333, 2012.

[4] J. Weinert, C. Ma, and C. Cherry, "The transition to electric bikes in China: history and key reasons for rapid growth," Transportation, vol. 34, no. 3, pp. 301-318, 2007.

[5] Y. Zhang, Y. Li, X. Yang, Q. Liu, and C. Li, "Built environment and household electric bike ownership," Transportation Research Record, no. 2387, pp. 102-111, 2013.

[6] "Bike-Europe. E-bike Sales Show Double Digit Growth in Main Markets, 2017," http://www.bike-eu.com/sales-trends/nieuws/ 2016/5/e-bike-sales-shows-double-digit-growth-in-mainmarkets-10126236.

[7] "Navigant Research, Electric Bicycles, 2017,” https://www .navigantresearch.com/research/electric-bicycles.

[8] "University of Waterloo WeBike Project," http://blizzard.cs .uwaterloo.ca/iss4e/webike-project. Retrieved April 2017.

[9] I. Rios, L. Golab, and S. Keshav, "Analyzing the usage patterns of electric bicycles," in Proceedings of the 2016 Workshop on Electric Vehicle Systems, Data, and Applications, EV-SYS 2016, can, June 2016.

[10] C. Cherry and R. Cervero, "Use characteristics and mode choice behavior of electric bike users in China," Transport Policy, vol. 14 , no. 3, pp. 247-257, 2007.

[11] B. Langford, C. Cherry, T. Yoon, S. Worley, and D. Smith, "North America's first E-bikeshare," Transportation Research Record, no. 2387, pp. 120-128, 2013. 
[12] J. G. Su, M. Winters, M. Nunes, and M. Brauer, "Designing a route planner to facilitate and promote cycling in Metro Vancouver, Canada," Transportation Research Part A: Policy and Practice, vol. 44, no. 7, pp. 495-505, 2010.

[13] M. Winters, M. Brauer, E. M. Setton, and K. Teschke, "Mapping bikeability: A spatial tool to support sustainable travel," Environment and Planning B: Planning and Design, vol. 40, no. 5, pp. 865-883, 2013.

[14] M. Winters, G. Davidson, D. Kao, and K. Teschke, "Motivators and deterrents of bicycling: Comparing influences on decisions to ride," Transportation, vol. 38, no. 1, pp. 153-168, 2011.

[15] C. Reynolds, M. Winters, F. Ries, and B. Gouge, "Active transportation in urban areas: exploring health benefits and risks," National Collaboration Centre for Environmental Health, 2010.

[16] B. Gojanovic, J. Welker, K. Iglesias, C. Daucourt, and G. Gremion, "Electric bicycles as a new active transportation modality to promote health," Medicine and Science in Sports and Exercise, vol. 43, no. 11, pp. 2204-2210, 2011.

[17] C. Kiefer and F. Behrendt, "Smart e-bike monitoring system: Real-time open source and open hardware GPS assistance and sensor data for electrically-assisted bicycles," IET Intelligent Transport Systems, vol. 10, no. 2, pp. 79-88, 2016.

[18] A. Fyhri and N. Fearnley, "Effects of e-bikes on bicycle use and mode share," Transportation Research Part D: Transport and Environment, vol. 36, pp. 45-52, 2015.

[19] J. Paefgen and F. Michahelles, "Inferring usage characteristics of electric bicycles from position information," in Proceedings of the 3rd International Workshop on Location and the Web, LocWeb 2010, pp. 16-19, November 2010.

[20] K. Flüchter and F. Wortmann, "Implementing the connected e-bike: challenges and requirements of an IoT application for urban transportation," in Proceedings of the The First International Conference on IoT in Urban Space, Rome, Italy, October 2014.

[21] J. Dill and G. Rose, "Electric bikes and transportation policy," Transportation Research Record, no. 2314, pp. 1-6, 2012.

[22] J. MacArthur, J. Dill, and M. Person, "Electric bikes in North America: Results of an online survey," Transportation Research Record, vol. 2468, pp. 123-130, 2014.

[23] J. MacArthur, N. Kobel, J. Dill, and Z. Mumuni, Evaluation of an Electric Bike Pilot Project at Three Employment Campuses in Portland, Oregon. NITC-RR-564B, Transportation Research and Education Center (TREC), Portland, 2017.

[24] M. Dozza, G. F. Bianchi Piccinini, and J. Werneke, "Using naturalistic data to assess e-cyclist behavior," Transportation Research Part F: Traffic Psychology and Behaviour, vol. 41, pp. 217-226, 2016.

[25] B. Langford, J. Chen, and C. Cherry, "Risky riding: Naturalistic methods comparing safety behavior from conventional bicycle riders and electric bike riders," Accident Analysis and Prevention, vol. 82, pp. 220-226, 2015.

[26] K. Schleinitz, T. Petzoldt, L. Franke-Bartholdt, J. Krems, and T. Gehlert, "The German Naturalistic Cycling Study - Comparing cycling speed of riders of different e-bikes and conventional bicycles," Safety Science, vol. 92, pp. 290-297, 2017.

[27] M. Johnson and G. Rose, "E-bike safety: Insights from a survey of Australian e-bike riders," in Transportation Research Board 95th Annual Meeting, pp. 16-3299, 2016.

[28] K. An, X. Chen, F. Xin, B. Lin, and L. Wei, “Travel characteristics of e-bike users: survey and analysis in Shanghai," Procedia Social and Behavioral Sciences, vol. 96, no. 6, pp. 1828-1838, 2013.
[29] S. Haustein and M. Moller, "Age and attitude: changes in cycling patterns of different e-bike user segments," International Journal of Sustainable Transportation, vol. 10, no. 9, pp. 836-846, 2016.

[30] N. Popovich, E. Gordon, Z. Shao, Y. Xing, Y. Wang, and S. Handy, "Experiences of electric bicycle users in the sacramento, california area," Travel Behaviour and Society, vol. 1, no. 2, pp. 37-44, 2014.

[31] L. Gebhard, L. Golab, S. Keshav, and H. Demeer, "Range prediction for electric bicycles," in Proceedings of the 7th International Conference on Future Energy Systems, e-Energy 2016, can, June 2016.

[32] S. D. Fink, L. Golab, S. Keshav, and H. de Meer, "How similar is the usage of electric cars and electric bicycles?" in Proceedings of the the workshop on Electric Vehicle Systems, Data and Applications (EV-Sys), pp. 334-340, Shatin, Hong Kong, May 2017.

[33] "Phidgets Inc. - Unique and Easy to Use USB Interfaces, 2017," http://www.phidgets.com/.

[34] T. Carpenter, Measuring Mitigating Electric Vehicle Adoption Barriers, University of Waterloo Ph.D. Dissertation, 2015. 


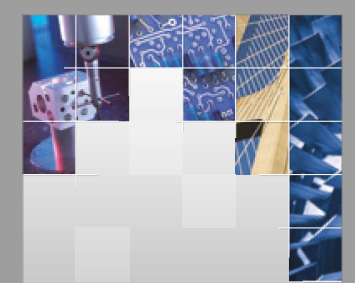

\section{Enfincering}
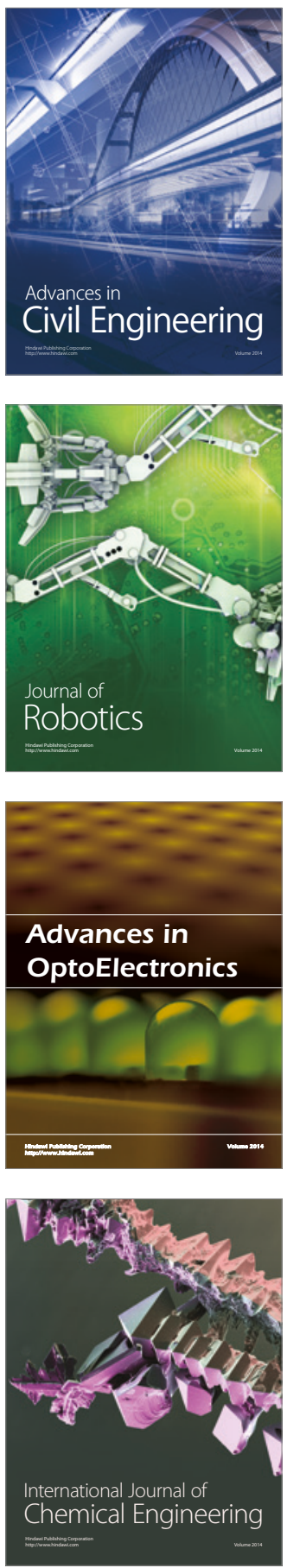

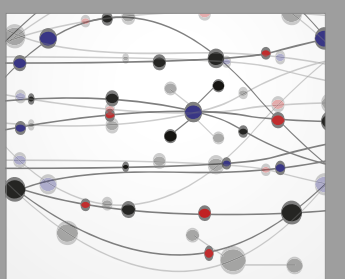

The Scientific World Journal

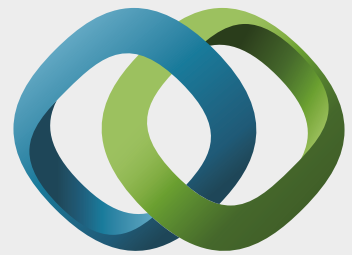

\section{Hindawi}

Submit your manuscripts at

https://www.hindawi.com
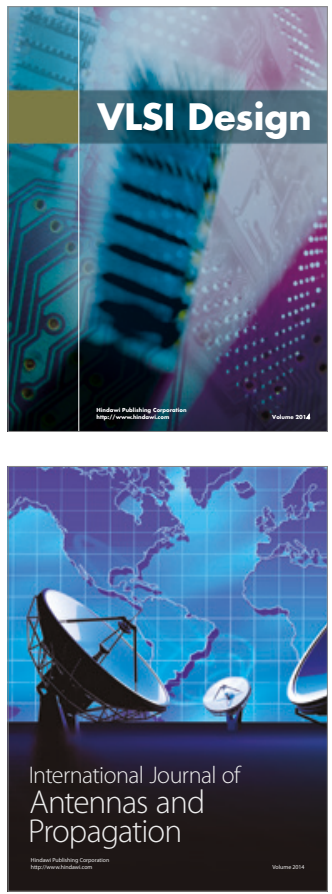

\section{Rotating}

Machinery
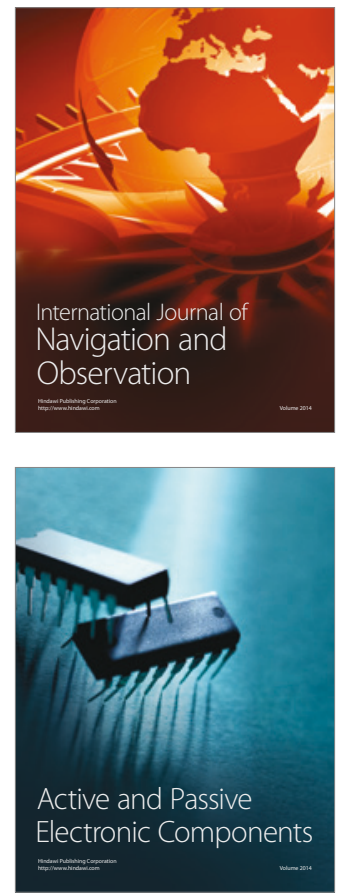
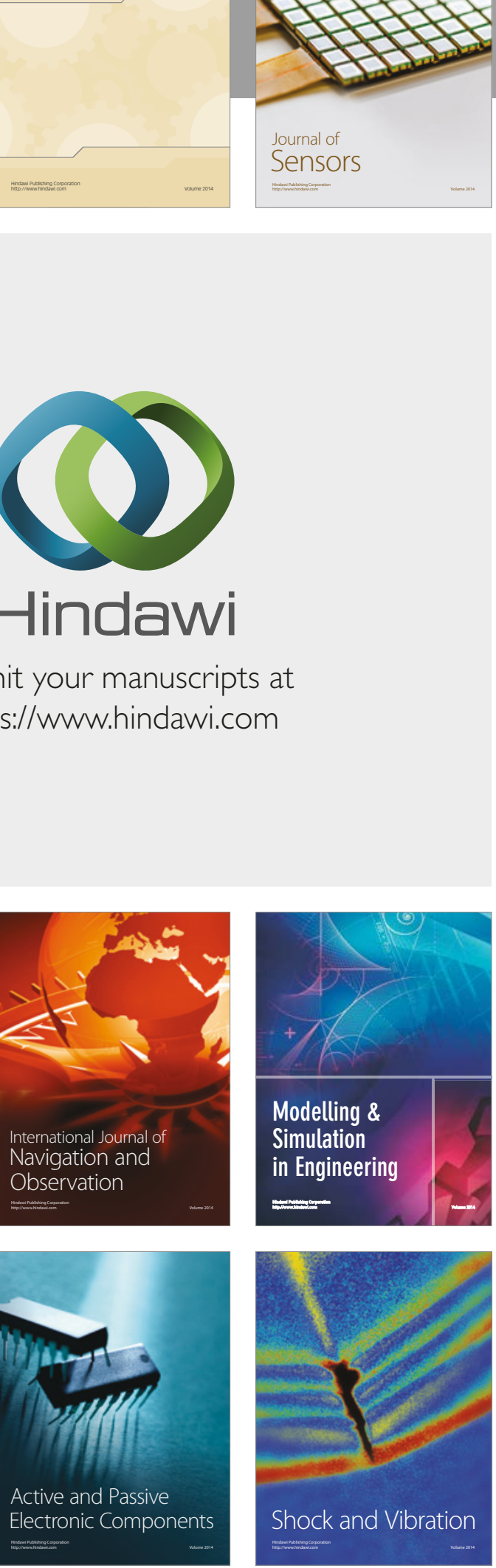
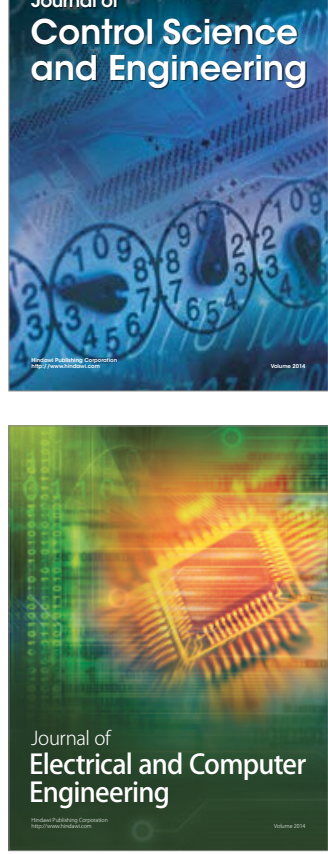

Distributed

Journal of

Control Science

and Engineering
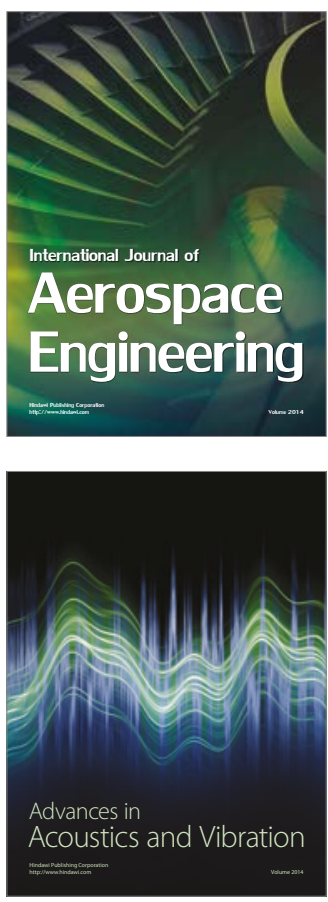

Sensor Networks 